\title{
High Quality Bio-Oil Obtained from Catalyzed Pyrolysis of Olive Mill Solid Wastes in a Bi-Functional Reactor
}

\author{
Nabil Tabaja ${ }^{*}$, Ahmad Kassas ${ }^{1}$, Soumaya Hamieh ${ }^{1}$, Rana Haidar' ${ }^{1}$, Maria-Laura Foddis ${ }^{2}$, \\ Joumana Toufaily ${ }^{*}$, T. Jean Daou ${ }^{3}$, Tayssir Hamieh ${ }^{1,4^{*}}$ \\ ${ }^{1}$ MCEMA and LEADDER Laboratories, Faculty of Sciences and EDST, Lebanese University, Hariri Campus, Beirut, \\ Lebanon \\ ${ }^{2}$ DICAAR_Dipartimento di Ingegneria Civile Ambientale e Architecttura, Università de Cagliari, Cagliari, Italy \\ ${ }^{3}$ Université de Haute Alsace, Université de Strasbourg, Axe Matériaux à Porosité Contrôlée (MPC), Institut de Science des \\ Matériaux de Mulhouse (IS2M), Mulhouse Cedex, France \\ ${ }^{4}$ Invited Researcher at SATIE-IFSTTAR, Université Gustave Eiffel, Campus de Marne-La-Vallée, Versailles, France \\ Email: ^nabil-tabaja@hotmail.fr, ‘joumana.toufaily@ul.edu.lb, ‘tayssir.hamieh@ul.edu.lb
}

How to cite this paper: Tabaja, N., Kassas, A., Hamieh, S., Haidar, R., Foddis, M.-L., Toufaily, J., Daou, T.J. and Hamieh, T. (2021) High Quality Bio-Oil Obtained from Catalyzed Pyrolysis of Olive Mill Solid Wastes in a Bi-Functional Reactor. Materials Sciences and Applications, 12, 52-77. https://doi.org/10.4236/msa.2021.121004

Received: November 27, 2020

Accepted: January 18, 2021

Published: January 21, 2021

Copyright $\odot 2021$ by author(s) and Scientific Research Publishing Inc. This work is licensed under the Creative Commons Attribution International License (CC BY 4.0).

http://creativecommons.org/licenses/by/4.0/

\begin{abstract}
Olive Mill Solid Wastes (OMSW) released in nature without any treatment is a major environmental problem in the Mediterranean region. In this work, the catalyzed pyrolysis of OMSW has been investigated. A catalyst based on SBA-15 mesoporous silica doped with chromium ferrite nanoparticles was prepared by the double solvent technique (DS). The prepared catalyst was characterized by scanning electron microscopy (SEM), Wide and Small Angle X-ray Scattering (WAXS, SAXS), Energy Dispersive X-ray (EDX) and FT-IR spectroscopies. Reverse spinel chromium ferrite nanoparticles were located inside the SBA-15 pores as confirmed by SEM images. The obtained catalyst was tested for pyrolysis reactions of OMSW. Several parameters were studied to optimize the conditions of the pyrolysis reaction in order to increase the bio-oil conversion yield. The GC-MS results demonstrated that the quality of the obtained bio-oil was improved by decreasing the quantity of phenolic and oxygenated components as well as the size of the obtained molecules. The produced bio-oil from pyrolysis of OMSW is identical to that obtained from the pyrolysis of commercial cellulose under the same conditions. A $37 \%$ conversion yield of bio-oil was obtained for the best conditions.
\end{abstract}

\section{Keywords}

Energy Conversion, Bio-Oil, Biomass, Pyrolysis Reactor, Olive Mill Solid Wastes, SBA-15 Mesoporous Silica 


\section{Introduction}

Due to the rapid population growth, urbanization and industrial development, the demand for energy resources is constantly increasing [1]. The current resources used to meet this demand are mainly conventional energies like charcoal, oil and natural gas [2]. The expenditures for energy supply were $10 \%$ of the word gross domestic product in 2011 [3]. Between 1990 and 2008, the world population increased by $27 \%$ where the global energy usage increased by $39 \%$ [4]. According to the International Energy Agency (IEA), a remarkable increase of energy demand by $2.3 \%$ was observed in 2018 . The IEA estimated that the energy demand would rise by $1.3 \%$ each year until 2040 [5]. Furthermore, the use of conventional energy is the main cause of atmospheric pollution with irreversible impacts on the environment such as global warming [1] [6] [7] [8] [9] [10]. Taking into consideration the increasing demand and environmental impacts, the use of alternative resources like renewable energy sources is essential to improve the security of energy supply [11] [12] [13]. In addition, increasing the use of renewable energy instead of fossil fuel, reduces the emission of greenhouse gases and therefore global warming [14] [15]. Indeed there are several energy resources with minimal impacts on the ecosystem such as wind, solar, water and biomass [16].

Biomass is the third largest energy resource after the primary coal and oil [17]. For developing countries, the use of biomass is of great importance because their economies are predominantly based on agriculture and the industrial sector is mainly food related. Various thermochemical and biochemical conversion processes such as carbonization, gasification, liquefaction, hydrogenation, pyrolysis, and anaerobic and methanol fermentation were used to convert biomass into energetic products [18] [19] [20] [21].

The production of olive oil is accompanied by a large amount of water (liquid) waste (OMWW) and solid waste (OMSW) [22]. The total annual world production of olive oil is 2.9 million tones, where $97 \%$ of this production is concentrated in the Mediterranean [23]. The amount of solid and liquid residues is a function of olive oil extraction technology [24] [25] [26]. However, for the Mediterranean countries, the removal of residues of olive mills (OMW) is considered a major environmental problem. The uncontrolled disposal of OMW in nature provokes powerful phytotoxic and antimicrobial effects because of its high chemical oxygen demand and the phenolic components present in the olive oil [27] [28] [29] [30] [31]. Several methods were performed to manage solid wastes. The impregnation of olive mill waste water (OMWW) on dry biomasses and (OMSW) is one of the strategies [32]. Researchers found that the mineral contents present in the OMWW accelerate the thermal degradation of dry biomasses. Pellets production used for domestic boilers have been investigated by Kraeim et al. [33] and Lajili et al. [34] [35]. Yet, an increase in particulates emission and residual ash content may limit the application of these pellets in domestic and industrial boilers. Other techniques are used for such purpose. Ag- 
glomeration, roasting and the use of solid wastes to ameliorate the fertility of soil are examples of these techniques [36] [37] [38]. Cellulose, hemicellulose and lignin are the main components of the olive mill solid wastes. The composition ratio of each component is affected by various parameters such as olive varieties and cultivation conditions [23]. Nevertheless, pyrolysis is an important technique for OMSW disposal. In this technique, biomass are heated to moderate temperatures, followed by a fast vapors quenching. This gives three main products, solid char, non-condensable gases, and a liquid phase which is known as bio-oil. The latter may represent up to $70 \mathrm{wt} \%$ of the raw biomass, which renders the process highly efficient [23] [39]. Many parameters affect the ratio and the quality of each product namely moisture removal, the temperature, the residence time in the reactor, the reaction atmosphere and the biomass compositions [40]-[45]. The bio-oil issued from pyrolysis has many important industrial applications. It can be used as combustible fuel, in the production of chemical products and as oil additive [43] [46] [47]. The use of a catalyst increases the conversion of lignocellulose into bio-oil and improves its quality. Such advance is obtained by increasing small size aromatic molecules formation, by cracking. In addition, reducing oxygen content while the products are still in the vapor phase (prior to condensation) enhances their quality by internal catalytic pyrolysis depending on the placement of the catalyst bed with respect to the pyrolysis reactor. Consequently, the use of catalyst increases the energy content of bio-oil, decreases its density and increases its solubility when used as a fuel additive. The catalysts selected for such reactions should have an activity, selectivity and thermal stability to maximize the yield and improve the quality of the bio-oil [48]. The basic catalysts are mainly Nobel metals like Mo/Ni [49] [50]. Acidic catalysts of micro and mesoporous materials such as HZSM-5, Al-MCM-41, MCM-48, USY are described in literature as pyrolysis catalysts. These materials can be modified by metal cations like $\mathrm{Al}, \mathrm{Cr}, \mathrm{Fe}$ etc. to improve the reactivity [51] [52] [53]. Acid catalysts, especially the microporous materials, are confronted with a rapid deactivation by the deposition of coke due to the large molecules in the pyrolysis vapor. The molecules cannot penetrate into the micropores of the zeolite, but eventually deposit in the form of coke on the surfaces of the catalyst. Then, the inhibition of the catalyst by coke accumulation leads to a low bio-oil yield during pyrolysis. Mesoporous acid catalysts, such as MCM-41, have the potential to break down large molecular oligomers into bio-oil but their low hydrothermal stability and high production cost limit their use for organic reactions [49].

In this work, a special pyrolysis reactor has been designated for two purposes. The first is to accelerate the pyrolysis of the OMSW. The second is to catalyze the cracking reactions before the condensation step where the pyrolysis products are in vapor phase to ameliorate the bio-oil quality. Different conditions have been studied such as final temperature, temperature ramp, and the use of catalyst (nature, mass and ratio). SBA-15 mesoporous silica modified by chromium 
ferrite nanoparticles have been used as catalyst. SBA-15 has a high thermal stability due to its thick silica framework and a large mesoporous diameter up to 30 $\mathrm{nm}$. In this study, SBA-15 was produced by a special method allowing to increase its specific surface area, its total pores volume, the connectivity between the mesopores, the main pores diameter and the number of functional groups present at the surface of the particles (mainly hydroxyl groups) was used as support [54]. The double solvent technique, which is a special replication technique, has been used to introduce the chromium ferrite nanoparticles inside the pores of the SBA-15. The special geometric form of the nanoparticles present in the porosity of SBA-15 mesopores enables our material to be micro-reactors that ameliorate the biomass cracking into bio-oil, accelerate products de-oxygenation and improve the bio-oil quality.

\section{Experimental Part}

\subsection{Materials}

Hydrochloric acid (37\%), polyethylene glycol Pluronic (P123) of general formula $\mathrm{EO}_{20} \mathrm{PO}_{70} \mathrm{EO}_{20}$, BASF corporation $\left(\mathrm{d}=1.018 \mathrm{~g} \cdot \mathrm{ml}^{-1}\right)$, tetraethyl orthosilicate (TEOS) of general formula $\mathrm{C}_{8} \mathrm{H}_{20} \mathrm{O}_{4} \mathrm{Si}$, $99 \%$ Sigma-Aldrich, $\mathrm{n}$-Hexane $\left(\mathrm{d}=0.6606 \mathrm{~g} \cdot \mathrm{ml}^{-1}\right)$, iron nitrate (III) nonahydrate $\left(\mathrm{Fe}\left(\mathrm{NO}_{3}\right)_{3}, 9 \mathrm{H}_{2} \mathrm{O}\right)$, chromium nitrate (III) nonahydrate $\left(\mathrm{Cr}\left(\mathrm{NO}_{3}\right)_{3}, 9 \mathrm{H}_{2} \mathrm{O}\right)$.

\subsection{Synthesis of SBA-15 in a Low-Acidic Medium}

Mesoporous SBA-15 was prepared by the sol-gel method described by Tabaja et al. [54] In this method, $329.75 \mathrm{ml}$ of distilled water were acidified with $8.395 \mathrm{ml}$ $\mathrm{HCl}$ (37\%) and then $17.9025 \mathrm{~g}$ of P123 were dissolved in the obtained acid aqueous solution. The thermostat connected to the reactor is set at $35^{\circ} \mathrm{C}$ and the solution is maintained under mechanical stirring. After the complete dissociation of P123, a clear solution was obtained. Then, $42 \mathrm{ml}$ of TEOS were added drop-wise to the solution with a burette. The stirring was stopped immediately after the addition of the TEOS and the temperature was maintained at $35^{\circ} \mathrm{C}$ for $63 \mathrm{~h}$ in static conditions (open beaker to evaporate ethanol obtained from the TEOS hydrolysis). Then, the obtained solution was suspended with its synthesis liquor in a $500 \mathrm{ml}$ autoclave and subjected to a hydrothermal treatment at $130^{\circ} \mathrm{C}$ in an oven for $33 \mathrm{~h}$. The solid phase was collected, filtered by Buchner and washed with distilled water several times $(1.5 \mathrm{~L})$. A white powder was obtained after drying in air for $24 \mathrm{~h}$. Finally, the pores of the powder were liberated by calcination in a furnace at a temperature of $500^{\circ} \mathrm{C}$ with a heating rate of $2^{\circ} \mathrm{C}$ $\min ^{-1}$ and maintained at this temperature for $6 \mathrm{~h}$. Then the SBA-15 was recovered and stored away from moisture.

\subsection{Preparation of Chromium Ferrite Nanoparticles Supported by SBA-15}

The catalyst was prepared from calcined SBA-15 using the double solvent me- 
thod as a replication technique. Only freshly calcined silica was used. $0.88 \mathrm{~g}$ of calcined SBA-15 was immersed in $35 \mathrm{ml}$ of an organic solvent (n-hexane) using a large $0.5 \mathrm{~L}$ mortar (alumina) and mixed well using the pestle. Then, $0.85 \mathrm{ml}$ of $\mathrm{Fe}\left(\mathrm{NO}_{3}\right)_{3} \cdot 9 \mathrm{H}_{2} \mathrm{O}$ of aqueous solution of concentration $1.264 \mathrm{M}$ were added drop by drop to the mixture followed by $0.85 \mathrm{ml}$ of $\mathrm{Cr}\left(\mathrm{NO}_{3}\right)_{3} \cdot 9 \mathrm{H}_{2} \mathrm{O}$ of aqueous solution of concentration $1.357 \mathrm{M}$ to obtain wt\% (percentage of weight) of $\mathrm{Fe}$ and $\mathrm{Cr}$ equal to $6 \mathrm{wt} \%$ for each metal in the final solid. In this case, salt precursor was directed into the pores of SBA-15 under the action of repulsive forces with the organic solvent. The solution was mixed well to homogenize and the n-hexane was removed then by sample decantation, and the obtained catalyst was left on a filter paper to dry for $24 \mathrm{~h}$ to evacuate organic solvent traces, before being stored uncalcined and named $\mathrm{Fe}(6) / \mathrm{Cr}(6)-\mathrm{SBA}_{-}(\mathrm{U})$. The prepared catalyst was thermally activated in air without flux in a muffle oven, at $2^{\circ} \mathrm{C} \cdot \mathrm{min}^{-1}$ up to $700^{\circ} \mathrm{C}$ (for $5 \mathrm{~h}$ ) and then removed from the oven to cool down at room temperature and named $\mathrm{Fe}(6) / \mathrm{Cr}(6)-\mathrm{SBA}_{-}(\mathrm{C})$. The quenching was used to avoid the formation of big crystals, and to introduce gaps inside the statures of the crystalline lattice.

\subsection{Catalytic Pyrolysis Reactions}

The pyrolysis reactions were carried out in a special designed reactor represented in Figure 1. First, the OMSW were thermally treated at $80^{\circ} \mathrm{C}$ for $48 \mathrm{~h}$ in an oven, and then the dried solid was ground into fine powder in a mortar. The thermal treatment of the OMSW is common for all pyrolysis reactions and it was used to remove moisture from the biomass. A desired mass of OMSW was introduced

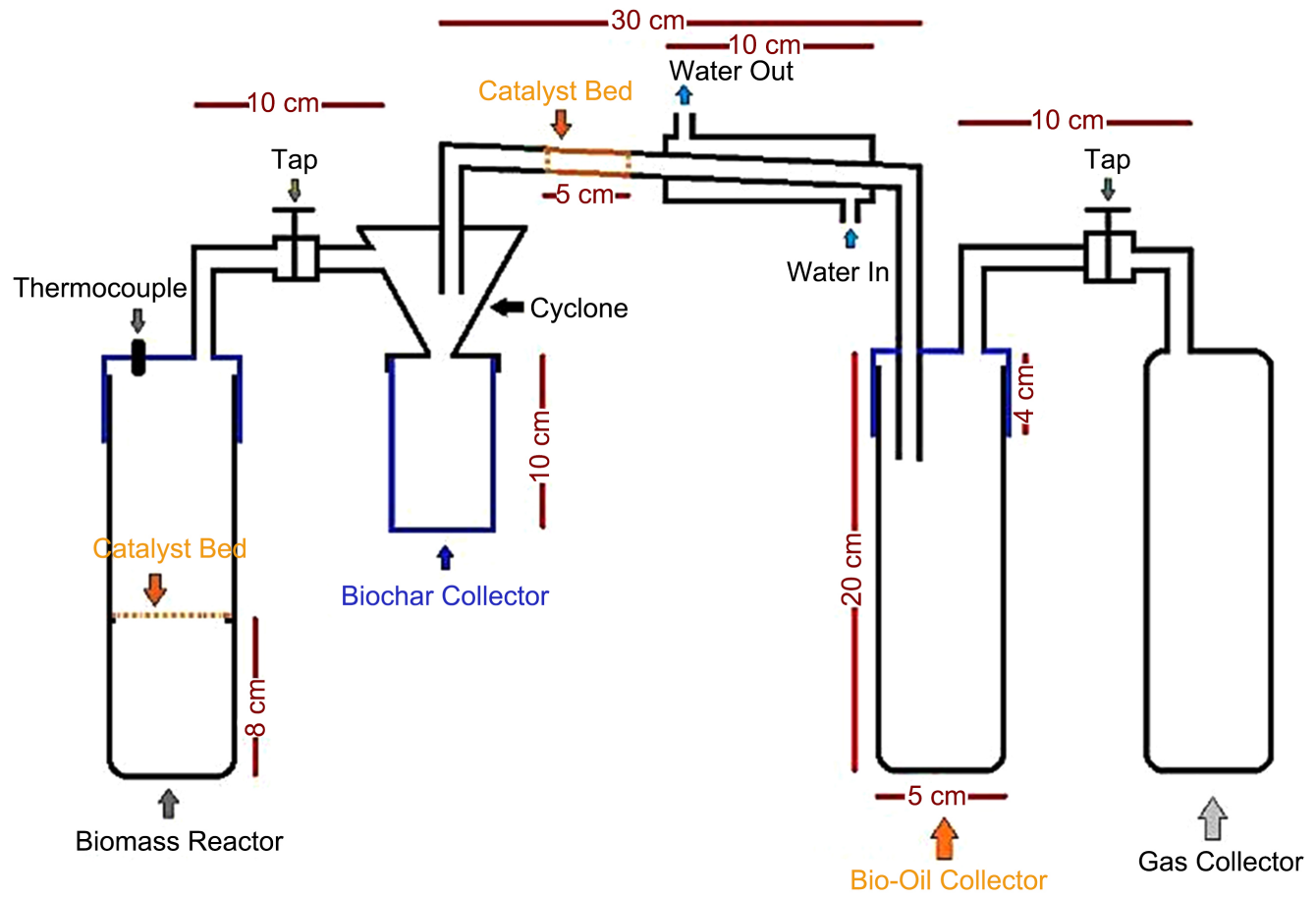

Figure 1. The designed reactor used in pyrolysis reactions. 
into the reactor and a desired mass of the catalyst was added into the catalytic bed inside the reactor. After installation of the catalytic bed, the reactor was closed and the pyrolysis conditions (temperature, temperature rate and residence time) were determined using digital programming system for temperature control. This is followed by degassing using nitrogen flow for $5 \mathrm{~min}$ with a gas tube related from the side of the thermocouple, and then the thermocouple is reinstalled. Consequently, the pyrolysis reactions were performed under nitrogen with and without catalyst at different temperatures $\left(200^{\circ} \mathrm{C}, 250^{\circ} \mathrm{C}, 350^{\circ} \mathrm{C}, 450^{\circ} \mathrm{C}\right.$ and $\left.550^{\circ} \mathrm{C}\right)$. Table 1 summarizes the conditions of the performed pyrolysis reactions.

Table 1 . The conditions of the performed pyrolysis reactions.

\begin{tabular}{|c|c|c|}
\hline Temperature $\left({ }^{\circ} \mathrm{C}\right)$ & $\begin{array}{l}\text { Temperature rate } \\
\left(\text { in }{ }^{\circ} \mathrm{C} \min ^{-1}\right)\end{array}$ & $\begin{array}{c}\text { Catalyst weight ratio (in g)/OMSW } \\
\text { or cellulose (in g) }\end{array}$ \\
\hline 200 & 10 & $0.2 / 15$ OMSW \\
\hline \multirow[t]{8}{*}{250} & 10 & $0.2 / 15$ OMSW \\
\hline & & 5 OMSW Without catalyst \\
\hline & & 0.3/5 OMSW \\
\hline & & 0.3/8 OMSW \\
\hline & & 0.3/10 OMSW \\
\hline & & 15 OMSW Without catalysts \\
\hline & & 0.1/15 OMSW \\
\hline & & $0.2 / 15$ OMSW \\
\hline \multirow[t]{8}{*}{350} & 10 & $0.3 / 15$ OMSW \\
\hline & & 1/15 OMSW \\
\hline & & 2/15 OMSW \\
\hline & & 15 cellulose No catalyst \\
\hline & & $0.1 / 15$ cellulose \\
\hline & & $0.2 / 15$ cellulose \\
\hline & & $0.3 / 15$ cellulose \\
\hline & & $1 / 15$ cellulose \\
\hline
\end{tabular}

15 OMSW Without catalysts

$0.1 / 15$ OMSW

$1 / 15$ OMSW

\begin{tabular}{ccc}
\hline 450 & 50 & 15 OMSW Without catalysts \\
& & $0.1 / 15$ OMSW \\
\hline 550 & 50 & $0.1 / 15$ OMSW \\
\hline 350 & 50 & $0.1 / 15$ OMSW \\
\hline
\end{tabular}




\subsection{Characterization of the Catalyst and the Analytical Techniques}

Phase identification of SBA-15, $\mathrm{Fe}(6) / \mathrm{Cr}(6)-\mathrm{SBA}$, and $\mathrm{Fe}(6) / \mathrm{Ni}(6)-\mathrm{SBA}$; (with and without calcination) were done using Wide and Small-Angles X-ray Scattering (SAXS and WAXS) and direct comparison with data in the ICDD (International Centre for Diffraction Data). Small Angle SAXS profiles allowed determining the mesopores organization and size of SBA-15. For WAXS measurements, a BRUKER AXS GMBH was used with $\mathrm{Cu}-\mathrm{Ka}_{1}$ radiation $\left(\lambda_{1}=1.54060 \AA\right)$ and $\mathrm{Cu}-\mathrm{Ka}_{2}$ radiation $\left(\lambda_{2}=1.54439 \AA\right)$ with elimination of $\mathrm{Cu}-\mathrm{K} \beta$ radiation $\left(\lambda_{3}=\right.$ $1.39222 \AA$ ) in the $2 \theta$ range from $0^{\circ}$ to $5^{\circ}$ in SAXS and from $5^{\circ}$ to $80^{\circ}$ in WAXS with scanning rate of $0.02^{\circ} / \mathrm{min}$. Peak positions and full width at half maxima (FWHM) can be obtained using different software (EVA or the Full Prof, free access on Web). The FWHM of the most intense diffraction can be used to evaluate coherent domain sizes using the Scherrer formula with a 0.9 constant factor introduced for spherical particles. The positions of peaks determine the crystalline structure of the crystalline nanoparticles where the FWHM determine the particle sizes.

Fourier Transfer Infra-Red (FTIR) spectra of SBA-15, $\mathrm{Fe}(6) / \mathrm{Cr}(6)-\mathrm{SBA}$, calcined and not calcined, before and after pyrolysis reactions has been recorded using JASCO FT/IR-6300 of resolution $\mathrm{R}=4 \mathrm{~cm}^{-1}$, [400 $\left.-4000 \mathrm{~cm}^{-1}\right]$ interval of wave number. FTIR has been used to determine the optical properties of the prepared powders especially the functional groups at the surface of the blank SBA-15 then the metal bond between the introduced metals, the silicate and the hydroxyl groups at the surface of the SBA-15.

The shape and the morphology of SBA-15 and $\mathrm{Fe}(6) / \mathrm{Cr}(6)-\mathrm{SBA}$ (with and without calcination); powders were obtained using a SEM-FEG HITACHI SU-70, with an operating voltage of acceleration of $1 \mathrm{kV}$ and a working distance of $1.4 \mathrm{~mm}$ from the sample. The location of the prepared nanoparticles after replication in SBA-15 was also determined using SEM.

Elementary study was performed on SBA-15 and $\mathrm{Fe}(6) / \mathrm{Cr}(6)-\mathrm{SBA}$ (with and without calcination) to determine wt $\%$ of elements in each of these materials especially the percentage of introduced metals ( $\mathrm{Fe}$ and $\mathrm{Cr}$ using AMETEK EDAX device to compare the results with the desired percentages.

Qualitative analysis of bio-oils obtained from pyrolysis reactions was carried out using GCMS-QP2010 Plus. Approximately $200 \mathrm{mg}$ of bio-oil were dissolved in $5 \mathrm{ml}$ of acetone. Prior to injection, the diluted samples were first dried with 1 $\mathrm{g}$ of anhydrous sodium sulfate in a beaker and filtered through a $0.22 \mu \mathrm{m}$ syringe filter. Chromatographic separation was performed using a HP-INNO Wax capillary column $(30 \mathrm{~m} \times 0.25 \mathrm{~mm} \times 0.25 \mu \mathrm{m})$. Helium $(99.9995 \%)$ was used as carrier gas at a flow rate of $1 \mathrm{ml} \cdot \mathrm{min}^{-1}$. The injector (7683B ALS) and the GC-MS interface were maintained at a constant temperature of $250^{\circ} \mathrm{C}$. A sample volume of $1 \mu \mathrm{l}$ was injected in split mode with a ratio of split of 20:1. The temperature ramps of the CPG oven were as follows: start heating to $50^{\circ} \mathrm{C}$ maintained for 2 
min, then at $90^{\circ} \mathrm{C}$ at a speed of $10^{\circ} \mathrm{C} \cdot \mathrm{min}^{-1}$, then at $120^{\circ} \mathrm{C}$ at a speed of $4^{\circ} \mathrm{C} \cdot \mathrm{min}^{-1}$, and then brought to $230^{\circ} \mathrm{C}$ at a speed of $8^{\circ} \mathrm{C} \cdot \mathrm{min}^{-1}$, and this final temperature was maintained for $10 \mathrm{~min}$ [55].

\section{Results and Discussion}

\subsection{Solid Physico-Chemical Properties}

The average weight percent of the elements $\mathrm{Si}, \mathrm{O}, \mathrm{C}, \mathrm{Cr}$ and $\mathrm{Fe}$ in the SBA-15 before $(\mathrm{U})$ and after $(\mathrm{C})$ calcination and in the samples $\mathrm{Fe}(6) / \mathrm{Cr}(6)-\mathrm{SBA}$ (U) and $\mathrm{Fe}(6) / \mathrm{Cr}(6)-\mathrm{SBA}_{-}(\mathrm{C})$ before and after pyrolysis reaction are presented in Table 2. The percentage of carbon decreases after calcination due to the elimination of the organic surfactant at $500^{\circ} \mathrm{C}$ for $6 \mathrm{~h}$ which influences the percentages of the elements $\mathrm{Si}$ and $\mathrm{O}$. Chromium and iron were absent in the calcined and the uncalcined SBA-15 material. After impregnation, the percentages of $\mathrm{Fe}$ and $\mathrm{Cr}$ in the catalyst before calcination were very close to the desired percentage for those elements ( $\sim 6 \mathrm{wt} \%)$. The average weight percentages of $\mathrm{Fe}$ and $\mathrm{Cr}$ increased up to $\sim 8 \mathrm{wt} \%$ after calcination. The experimental measurements were performed in the same sample at different locations. This increase from the desired percentage of both metals, $\mathrm{Fe}$ and $\mathrm{Cr}$, is related to further decrease in carbon contents from the SBA-15, after calcination at higher temperature $\left(700^{\circ} \mathrm{C}\right)$, from 2.8 to $2.1 \mathrm{wt} \%$. The average percentages of $\mathrm{Fe}$ and $\mathrm{Cr}$ in the catalyst after a pyrolysis reaction decreases to the half. This decrease corresponds to an increase in the ratio of carbon and not to the metallic elements loss during the catalytic reaction. The carbon weight percentage increased from $2 \mathrm{wt} \%$ before the reaction to $19 \mathrm{wt} \%$ after reaction. The observed carbon was assigned to the pyrolysis products which were adsorbed on the surface of the catalyst during the reaction.

SEM micrographs displaying the grain morphology of SBA-15 and SBA-15 modified with chromium ferrite prepared under the same conditions (without metallization) are shown in Figure 2. The SBA-15 particles presented in Figure 2(A) had uniform smooth hexagonal morphology with very short length. The particles have a uniform average size of average diameter of $2 \mu \mathrm{m}$, and an average thickness of $0.5 \mu \mathrm{m}$. Figure 2(B) is a micrograph of the $\mathrm{Fe}(6) / \mathrm{Cr}(6)-\mathrm{SBA}(\mathrm{C})$.

Table 2. The weight percentage of each element in each sample.

\begin{tabular}{cccccc}
\hline Samples & \multicolumn{5}{c}{ The average mass of elements in wt\% } \\
SBA-15 calcined & Si & O & C & Cr & Fe \\
SBA-15 not calcined & 55 & 41 & 3 & - & - \\
Fe (6)/Cr(6)-SBA_(C) & 30 & 36 & 34 & 9 & 6 \\
Fe (6)/Cr(6)-SBA_(U) & 49 & 31 & 2 & 7 & 4 \\
Fe (6)/Cr(6)-SBA_(C) & 45 & 37 & 3 & 4 & 4 \\
after a catalytic pyrolysis reaction & 31 & 38 & & & \\
\hline
\end{tabular}




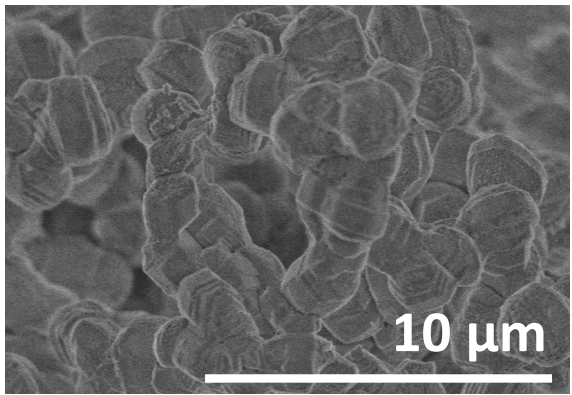

(A)

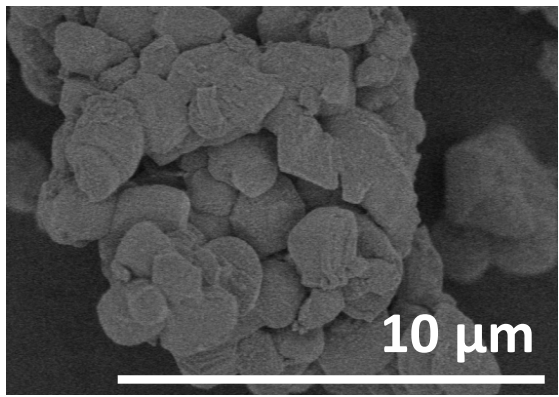

(B)

Figure 2. SEM micrographs of (A) SBA-15 calcined and (B) $\mathrm{Fe}(6) / \mathrm{Cr}(6)-\mathrm{SBA}$ (C) obtained under the same conditions as the catalyst prepared.

This micrograph shows no external chromium ferrite nanoparticle at the surface of the SBA-15. The absence of nanoparticles at the external surface of the SBA15 particles, the presence of metal elements ( $\mathrm{Fe}$ and $\mathrm{Cr}$ ) in the elementary analyses done by EDX and the presence of metal oxides nanoparticles (iron oxides and chromium ferrite) detected by XRD presented later, proves that these nanoparticles are located inside the pores of SBA-15. Tabaja et al., demonstrated this internal location of the nanoparticles within the SBA-15 pores when using the iron nitrate precursors instead of iron chloride in the double solvent replication technique [56].

The distribution of the mesopores of SBA- 15 after calcination at $500^{\circ} \mathrm{C}$ for $6 \mathrm{~h}$ was examined by Small Angle X-Ray Diffraction (SAXS). The diffraction pattern of the calcined SBA-15 shown in Figure 3(A) has three diffraction peaks which correspond to (100), (110) and (200) planes. These planes are correlated with a 2D hexagonal lattice. The indexed diffraction peak (100) appearing at lower angles was the most intense. Both diffractions indexed (110) and (210) were detected between $1.5^{\circ}$ and $2.2^{\circ}$ in $2 \theta$ angle.

Figure 3(B) represents the Wide Angle X-Ray Diffraction patterns (WAXS) of the SBA- 15 before $(\mathrm{U})$ and after $(\mathrm{C})$ calcination, and of the samples $\mathrm{Fe}(6) / \mathrm{Cr}(6)-\mathrm{SBA}$ before and after calcination at $700^{\circ} \mathrm{C}$. The diffractograms are compared with a spinel structure (cubic structure) diffractogram of maghemite or magnetite (space group F d-3 $\mathrm{m}$ ) prepared using the precipitation method and with a hematite lattice (rhombohedra structure, space group R-3c). The indexations of the peaks were based on the database ICDD files 25-1402 and 33-0664 relatives of the two crystalline phases. The diffraction patterns of the SBA-15 before and after calcination, as well as the catalyst without calcination, showed only a large diffraction peak in the region of $15^{\circ}$ to $35^{\circ} 2 \theta$, corresponding to amorphous silica material, indicating the absence of any crystallization in the samples. The diffraction pattern of $\mathrm{Fe}(6) / \mathrm{Cr}(6)-\mathrm{SBA}_{-}(\mathrm{C})$ showed two main diffraction peaks at $35^{\circ}$ and $63^{\circ}$ $(2 \theta)$. These two main peaks could be indexed to (311) and (440) planes respectively in a face centered cubic lattice, which could be attributed to a spinel phase of $\mathrm{CrFe}_{2} \mathrm{O}_{4}$ like the one observed for magnetite $\mathrm{Fe}_{3} \mathrm{O}_{4}$ (direct spinel), or maghemite $\gamma-\mathrm{Fe}_{2} \mathrm{O}_{3}$ (inverse spinel). The attribution to a maghemite $\gamma-\mathrm{Fe}_{2} \mathrm{O}_{3}$ structure 
was confirmed in this case by the absence of the indexed diffraction peak (111) which is expected at low angles. Therefore, $\mathrm{CrFe}_{2} \mathrm{O}_{4}$ is an inverse spinel structure in our preparation conditions. In this case, $\mathrm{Fe}^{2+}$ cations occupy the tetrahedral sites whereas half of the trivalent $\mathrm{Fe}^{3+}$ and $\mathrm{Cr}^{3+}$ occupy octahedral and tetrahedral sites in equal ratio. The diffraction peaks at $24^{\circ}, 34^{\circ}, 36^{\circ}, 50^{\circ}, 55^{\circ}, 63^{\circ}$ and $65^{\circ} 2 \theta$ are attributed to the presence of hematite rhombohedra structure. The intensity inversion of the two peaks at $34^{\circ}$ and $36^{\circ}$ (in pure hematite the peak at 34 is more intense), is related to the presence of the inverse spinel structure that have a diffraction peak at $35^{\circ} 2 \theta$.

The optical properties of the white silica SBA-15 before and after calcination and the prepared catalyst $\mathrm{Fe}(6) / \mathrm{Cr}(6)-\mathrm{SBA}$ before and after calcination at $700^{\circ} \mathrm{C}$ were analyzed by FT-IR. The results represented in Figure 4 are shown as a transmission percentage.

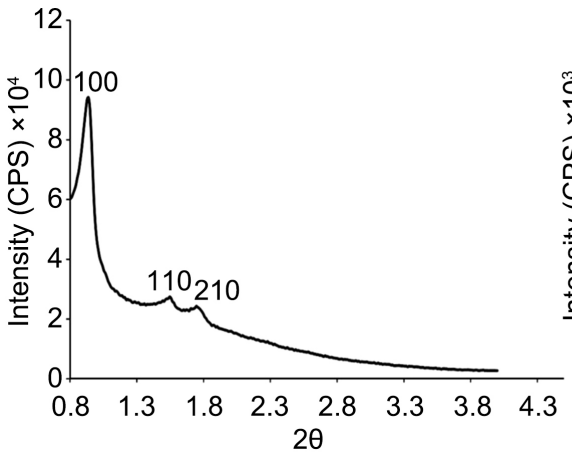

(A)

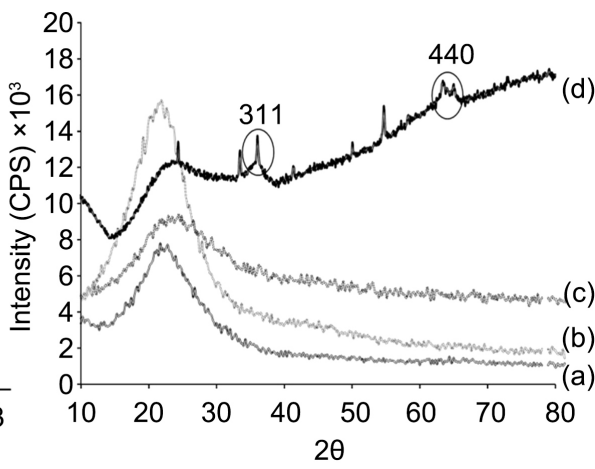

(B)

Figure 3. (A) SAXS of SBA-15 after calcination at $500^{\circ} \mathrm{C}$ for $6 \mathrm{~h}$. (B) Diffraction patterns (WAXS) of the samples: (a) SBA-15_(C), (b) SBA-15_(U), (c) $\mathrm{Fe}(6) / \mathrm{Cr}(6)-\mathrm{SBA} \_(\mathrm{U})$ and (d) $\mathrm{Fe}(6) / \mathrm{Cr}(6)-\mathrm{SBA}_{-}(\mathrm{C})$.

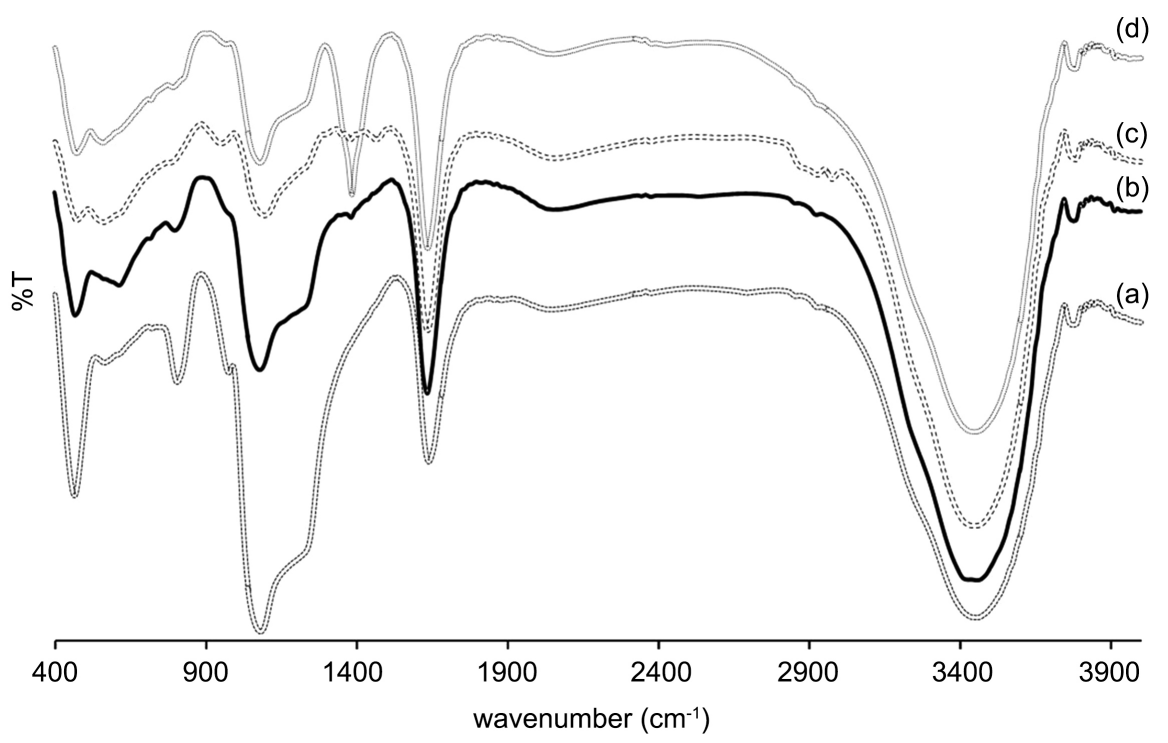

Figure 4. FT-IR spectra obtained on the samples: (a) SBA-15_(C), (b) $\mathrm{Fe}(6) / \mathrm{Cr}(6)-\mathrm{SBA}(\mathrm{C})$, (c) SBA-15_(U) and (d) Fe(6)/Cr(6)-SBA_(U). 
The peaks around 1061, 793 and $453 \mathrm{~cm}^{-1}$ in the SBA-15 spectrum represent $\mathrm{Si}-\mathrm{O}-\mathrm{Si}$ in the walls of the SBA-15, while the band centered around $965 \mathrm{~cm}^{-1}$ is typically from vibration of $\mathrm{Si}-\mathrm{O}$ in the $\mathrm{Si}-\mathrm{OH}$ groups represents the Brønsted acid and base sites of SBA-15. The peak at $1061 \mathrm{~cm}^{-1}$ becomes more intense after calcination. This increase can be attributed to the elimination of surfactants while the pores are released and the Si-O-Si becomes accessible to IR radiation.

In the specters of SBA-15, not modified, before and after calcination, the small band at $3756 \mathrm{~cm}^{-1}$ corresponds to $\mathrm{O}-\mathrm{H}$ stretching and vibration modes of isolated silanol inside the micropores of SBA-15. This silanol groups have weak Bronsted acid properties [57] [58]. The large and intense peak centered at 3419 $\mathrm{cm}^{-1}$, includes different stretching-vibration modes of different $\mathrm{O}-\mathrm{H}$ groups mainly at the surface and in the mesopores of the SBA-15. These groups can be divided into two: firs group for the absorption bands around $3419 \mathrm{~cm}^{-1}$ related to the silanol groups of medium Bronsted acidity and the second group for the absorption at lower frequency, around $3230 \mathrm{~cm}^{-1}$, for the silanol groups of strong Bronsted acidity [57]. The small intensity of the corresponding band of the isolated silanol groups can be related to the synthesis condition of the SBA that contains a maturation step at $35^{\circ} \mathrm{C}$ which transform micropores into mesopores. Another intense absorption band, corresponding to surface silanol groups, located at 1629 $\mathrm{cm}^{-1}$ is observed. The large surface area of the peaks centered at 3419 and 1629 $\mathrm{cm}^{-1}$ prove that the surface silanol groups of medium and strong Bronsted acidity are of high concentration in our SBA-15. After calcination, the broad peak of the $\mathrm{O}-\mathrm{H}$ groups in SBA-15 has become smaller due to the elimination of water molecules which are adsorbed on the surface of SBA-15 before calcination. Moreover, silanol groups were reduced in SBA-15 after calcination.

The FT-IR spectrum of SBA-15 modified by the iron and the chromium shows broad bands at about $580-560 \mathrm{~cm}^{-1}$, characteristic of $\mathrm{M}$ bonds in the metal oxide structures. These peaks correspond to the transition metal absorption, $\mathrm{Fe}$ and $\mathrm{Cr}$, within the metal oxide $\mathrm{FeO}$ and $\mathrm{CrO}$ respectively, representing the metal or the Lewis acid sites. The band centered around $965 \mathrm{~cm}^{-1}$ that present in the FT-IR spectrum of SBA-15 is slightly modified and shifted after modification by the iron and the chromium and its intensity decrease. These modifications were attributed to the interaction between the introduced metals and the surface $\mathrm{Si}-\mathrm{OH}$ and the formation of OM links (Oxygen-Metal). A slight shift from 1061 to $1058 \mathrm{~cm}^{-1}$ was observed in the specific band of Si-O-Si after metal modification. The peak at $3759 \mathrm{~cm}^{-1}$ of isolated $\mathrm{O}-\mathrm{H}$ groups is not modified after impregnation or metal ions. The modification of the broad band centered at $3419 \mathrm{~cm}^{-1}$ is not possible, otherwise, the band centered at $1629 \mathrm{~cm}^{-1}$ is shifted $20 \mathrm{~cm}^{-1}$ toward smallest wavenumber after modification by the metal salts (in the two catalysts, before and after calcination). This shift of the corresponding $\mathrm{O}-\mathrm{H}$ vibration band is very important to prove the modification of the Bronsted acid properties of the supported silica. A large $\Delta v$ of $\mathrm{O}-\mathrm{H}$ groups toward small frequency is attributed to a modification of the Bronsted sites prop- 
erties toward strong acidity [57] [58]. A peak at $1380 \mathrm{~cm}^{-1}$ appeared only in the spectrum of the catalyst before calcination. This peak was attributed to the nitrate molecules $\left(\mathrm{NO}^{3-}\right)$ adsorbed to the pore walls of the SBA-15. The formation of the nanoparticles at the surface of the SBA-15, that insure the stability of the formed oxide nanoparticles, can be explained by a mechanism of two steps. First, a physical interaction between the nitrates and the hydroxyl groups at the surface of the walls of the silica pores of SBA-15 has occurred, followed by the formation of $\mathrm{Si}-\mathrm{Fe}, \mathrm{Si}-\mathrm{O}-\mathrm{Fe}$ or $\mathrm{Si}-\mathrm{N}-\mathrm{Fe}$ after calcination. This mechanism explains the appearance of the peak around $1380 \mathrm{~cm}^{-1}$ and the decrease in the intensity of the bands at $3419 \mathrm{~cm}^{-1}$ in the spectrum of the catalyst after the introduction of the metal precursors and before calcination and then, the peak at $1380 \mathrm{~cm}^{-1}$ disappears and the intensity of the absorption band around $960 \mathrm{~cm}^{-1}$ decreases after calcination. The optical properties of both SBA-15 and modified SBA-15 demonstrated the presence of both Bronsted (hydroxyl groups) and Lewis acid sites (reducing sites). These active sites, in addition to the chemical, thermal and mechanical stability of the catalyst, are important factors in catalyzed pyrolysis for primary (de-polymerization) and secondary (fragmentation) reactions. The introduction of the chromium ferrite nanocrystals created additional active sites (Lewis acid sites, reducing sites) which accelerated the in-situ de-oxygenation reactions such as decarbonylation, decarboxylation, dehydration, aromatization and condensation, cracking, ketonisation etc. [59].

\subsection{The Results of Pyrolysis Reactions}

To study the activity of the prepared catalyst in pyrolysis reactions, blank pyrolysis reactions on commercial cellulose were performed at $350^{\circ} \mathrm{C}$ with a temperature rate of $10^{\circ} \mathrm{C} \mathrm{m^{-1 }}$. These reactions were carried out on $15 \mathrm{~g}$ of cellulose with different catalyst masses. The conditions and the results are summarized in Table 3. The results showed that the use of $100 \mathrm{mg}$ of catalyst increased the conversion yield of bio-oil from $25 \%$ to $37 \%$. This yield decreased to $23 \%$ as the mass of the catalyst increased to $1 \mathrm{~g}$. The decrease of bio-oil conversion yield was accompanied with an increase in the conversion yield of the bio-gas which increased from $44 \%$ to $61 \%$ when the catalyst mass was multiplied by 10 . According

Table 3. The effect of the mass of the catalyst on the conversion yield of the pyrolysis products on cellulose.

\begin{tabular}{cccc}
\hline Catalyst mass (mg) & Bio-char yield & Bio-oil yield & Bio-gas yield \\
\hline without catalyst & $18 \%$ & $25 \%$ & $57 \%$ \\
100 & $19 \%$ & $37 \%$ & $44 \%$ \\
200 & $18 \%$ & $33 \%$ & $49 \%$ \\
300 & $16 \%$ & $25 \%$ & $59 \%$ \\
1000 & $16 \%$ & $23 \%$ & $61 \%$ \\
\hline
\end{tabular}


to Zanzi et al. and Zabaniotou et al., these results were attributed to an increase in the cracking rate with the increase of the number of the active sites [60] [61] [62].

Pyrolysis reactions were performed to study the activity and the effect of the prepared catalyst on the yield of bio-oil conversation and its quality. Several conditions that can affect the yields of pyrolysis reaction were investigated. The effect of the mass of the OMSW, the weight ratio OMSW/catalyst and the temperature were studied.

Pyrolysis reactions, without catalysts, and with different OMSW masses, different temperatures and different temperature ramps were performed. The reaction conditions and the obtained yields of bio-char, bio-oil and bio-gas are summarized in Table 4 . An increase of bio-oil conversion from $8 \%$ to $24 \%$ was observed, whereas the bio-char yield is reduced when the mass of OMSW increase from $5 \mathrm{~g}$ to $15 \mathrm{~g}$. More bio-char and less bio-gas conversion yields were obtained compared to pure cellulose. This observation can be explained by the presence of lignin in OMSW that reduces bio-oil and bio-gas conversion and increase bio-char yield [62]. The increase of maximum temperature from 350 to $450^{\circ} \mathrm{C}$ substantially reduced the yield of bio-oil conversion and significantly increased the bio-gas conversion. This variation can be explained by the fact that the flash point of OMSW was reached. The most important bio-oil ratio was obtained at $350^{\circ} \mathrm{C}, 10^{\circ} \mathrm{C} \cdot \mathrm{min}^{-1}$ for $15 \mathrm{~g}$ of OMSW. The temperature ramp has almost no effect on the conversion yields when it is increased from $10^{\circ} \mathrm{C} \cdot \mathrm{min}^{-1}$ to $50^{\circ} \mathrm{C} \cdot \mathrm{min}^{-1}$ ). This shift is not very important. Whereas, higher speeds (fast pyrolysis) may increase slightly the bio-oil conversion yield. Another reaction was performed on SBA-15 before modification by metal salts. The reaction was performed with $100 \mathrm{mg}$ of non-modified calcined SBA-15 and $15 \mathrm{~g} \mathrm{OMSW}$ at $350^{\circ} \mathrm{C}$, $10^{\circ} \mathrm{C} \cdot \mathrm{min}^{-1}$. A similar result to that without any catalyst was obtained with a biooil yield of $24 \%$.

Pyrolysis reactions were carried out at $350^{\circ} \mathrm{C}$ with a temperature rate of $10^{\circ} \mathrm{C} \cdot \mathrm{min}^{-1}$ with different $\mathrm{OMSW} /$ catalyst weight ratio. In such reactions, the catalyst mass was fixed at $300 \mathrm{mg}$ where the mass of OMSW was changed. The results are summarized in Table 5. The experimental results showed an increase of

Table 4. The effect of the OMSW mass, the temperature and the temperature rate on the yield of pyrolysis products in the absence of catalyst.

\begin{tabular}{cccc}
\hline & Bio-char yield & Bio-oil yield & Bio-gas yield \\
\hline $5 \mathrm{~g} \mathrm{OMSW} ; 350^{\circ} \mathrm{C} ; 10^{\circ} \mathrm{C} \cdot \mathrm{min}^{-1}$ & $42 \%$ & $8 \%$ & $50 \%$ \\
$15 \mathrm{~g} \mathrm{OMSW} ; 350^{\circ} \mathrm{C} ; 10^{\circ} \mathrm{C} \cdot \mathrm{min}^{-1}$ & $29 \%$ & $24 \%$ & $47 \%$ \\
$15 \mathrm{~g} \mathrm{OMSW} ; 450^{\circ} \mathrm{C} ; 10^{\circ} \mathrm{C} \cdot \mathrm{min}^{-1}$ & $27 \%$ & $16 \%$ & $57 \%$ \\
$15 \mathrm{~g} \mathrm{OMSW} ; 450^{\circ} \mathrm{C} ; 50^{\circ} \mathrm{C} \cdot \mathrm{min}^{-1}$ & $25 \%$ & $17 \%$ & $58 \%$ \\
\hline
\end{tabular}


Table 5. The effect of the OMSW/catalyst weight ratio on the conversion yield of pyrolysis products. The reactions were performed at $350^{\circ} \mathrm{C}$ with a rate of $10^{\circ} \mathrm{C} \cdot \mathrm{min}^{-1}$.

\begin{tabular}{cccc}
\hline OMSW/catalyst weight ratio & Bio-char yield & Bio-oil yield & Bio-gas yield \\
\hline 27 & $37.5 \%$ & $27.5 \%$ & $35 \%$ \\
34 & $38 \%$ & $26 \%$ & $36 \%$ \\
50 & $27 \%$ & $33 \%$ & $40 \%$ \\
15 g OMSW without catalyst & $29 \%$ & $24 \%$ & $47 \%$ \\
\hline
\end{tabular}

the bio-oil conversion yield from $24 \%$ to $33 \%$ and a decrease of bio-gas conversion yield from $47 \%$ to $40 \%$ when $300 \mathrm{mg}$ of catalyst were used (OMSW/catalyst wt. ratio $=50 \mathrm{wt} \%)$. The most interesting result was the significant increase in biooil conversion yield with the increasing weight ratio OMSW/catalyst. The conversion yield of bio-oil increased from $27.5 \%$ to $33 \%$ with the increase of OMSW/ catalyst weight ratio from 27 to 50 . This observation proves the effect of the catalyst in the secondary reactions (cracking recombination, de-oxygenation...), after depolimerization and fragmentation which exist in the two cases. Therefore, more depolemerization and fragmentation products lead to more bio-oil conversion.

The same reactions were performed but with a constant mass of OMSW (15 g) but by changing the catalyst mass to change the OMSW/Catalyst weight ratio. The results are summarized in Table 6 . The same observation was obtained. The bio-oil conversion ratio decreased with the decrease of OMSW/catalyst weight ratio (increase of the catalyst weight). An important conversion yield of bio-oil of $35 \%$ was obtained with a weight ratio OMSW/catalyst of 150 (100 mg of catalyst). This conversion yield is significant compared to $27 \%$ obtained with activated alumina by Sensoz et al. under the same conditions [63]. Otherwise, 37 wt $\%$ liquid yields were obtained Sensoz et al. at $500^{\circ} \mathrm{C}$. A decrease in bio-oil conversion is observed at smallest ratios accompanied by an increase in bio-gas conversion ratio. This decrease can be explained by increasing cracking rate, with the increase in the number of the active sites and proved by the significant increase of bio-gas conversion yield. The same results were observed by Encinar et al. but using dolomite activated as catalysts. An increase in catalyst mass decrease liquid conversion and increase gas yield [64]. Demiral et al. obtained 37 $\mathrm{wt} \%$ and $31 \mathrm{wt} \%$ by using activated alumina and sodium fold spar respectively at $500^{\circ} \mathrm{C} / 10^{\circ} \mathrm{C} \cdot \mathrm{min}^{-1}$ but with a ratio $40 \%$ catalyst/solid [65]. By comparing our best results obtained over our catalyst with $0.6 \%$ ratio of catalyst/solid, the Lewis and Bronsted acid sites created at the surface and in the mesopores of the SBA-15 show high activity in the conversion into liquid products either at lower temperature.

The same effect of the maximum temperature was obtained with and without catalyst. The conversion yield of bio-oil decreased from $35 \%$ at $350^{\circ} \mathrm{C}$ to $24 \%$ at $450^{\circ} \mathrm{C}$. The results are summarized in Table 7. The results showed that the presence of the catalyst at $450^{\circ} \mathrm{C}$ with a rate of $10^{\circ} \mathrm{min}^{-1}$ increased the conversion 
yield of bio-oil from $16 \%$ (Table 4) to $24 \%$. Bio-oil conversion decreased significantly at the same temperature $\left(450^{\circ} \mathrm{C}\right)$ to $19 \%$ when the mass of the catalyst increased to $1 \mathrm{~g}$. A significant increase to $57 \%$ of bio-gas conversion yield was obtained in these conditions.

Pyrolysis reactions at lower temperatures $\left(200^{\circ} \mathrm{C}\right.$ and $\left.250^{\circ} \mathrm{C}\right)$ were performed. The results are summarized in Table 8. The low conversion yield into bio-oil and bio-gas observed at $200^{\circ} \mathrm{C}$ is attributed to the effect that the decomposition (primary reactions) of the biomass was very low at this temperature. Valenzuela-Calahorro et al. find the same results where an increase in bio-char yield was observed at low temperatures [66]. The conversion yield of bio-oil increased with temperature to reach its maximum at $350^{\circ} \mathrm{C}$ and then decreased to $24 \%$ at $450^{\circ} \mathrm{C}$ where the flash point was reached.

Pyrolysis reactions at $350^{\circ} \mathrm{C}$ and $450^{\circ} \mathrm{C}$ but at two different temperature rates, 10 and $50^{\circ} \mathrm{C} \cdot \mathrm{min}^{-1}$ were performed. The conditions and the results are summarized in Table 9. At $450^{\circ} \mathrm{C}$, the bio-oil conversion yield increased from $24 \%$ to $27 \%$ with the increase of temperature rate from $10^{\circ} \mathrm{C} \cdot \mathrm{min}^{-1}$ to $50^{\circ} \mathrm{C} \cdot \mathrm{min}^{-1}$. This effect was confirmed by the decrease of the residence time at flash point. A reverse effect was observed at $350^{\circ} \mathrm{C}$, where a significant decrease from $35 \%$ to $30 \%$ was obtained.

Table 6. The effect of increasing the weight of the catalyst on the yield of pyrolysis products. The reactions were performed at $350^{\circ} \mathrm{C}$ with a rate of $10^{\circ} \mathrm{C} \cdot \mathrm{min}^{-1}$ and with a fixed mass of OMSW $15 \mathrm{~g}$.

\begin{tabular}{cccc}
\hline OMSW/Catalyst ratio & Bio-char yield & Bio-oil yield & Bio-gas yield \\
\hline without catalyst & $29 \%$ & $24 \%$ & $47 \%$ \\
150 & $27 \%$ & $35 \%$ & $38 \%$ \\
75 & $29 \%$ & $35 \%$ & $36 \%$ \\
50 & $27 \%$ & $33 \%$ & $40 \%$ \\
15 & $28 \%$ & $17 \%$ & $55 \%$ \\
7.5 & $28 \%$ & $20 \%$ & $52 \%$ \\
\hline
\end{tabular}

Table 7. The effect of the variation of the mass of catalyst and temperature on the conversion yield of the pyrolysis products. The reactions were performed with the same $15 \mathrm{~g}$ of OMSW and temperature rate of $10^{\circ} \mathrm{C} \cdot \mathrm{min}^{-1}$.

\begin{tabular}{rccc}
\hline & Bio-char yield & Bio-oil yield & Bio-gas yield \\
\hline $100 \mathrm{mg}$ of the catalyst at $350^{\circ} \mathrm{C}$ & $27 \%$ & $35 \%$ & $38 \%$ \\
$100 \mathrm{mg}$ of the catalyst at $450^{\circ} \mathrm{C}$ & $25 \%$ & $24 \%$ & $51 \%$ \\
$1 \mathrm{~g}$ of the catalyst at $450^{\circ} \mathrm{C}$ & $24 \%$ & $19 \%$ & $57 \%$ \\
\hline
\end{tabular}


Table 8. The effect of temperature on the conversion yield of pyrolysis products. The reactions were carried out with $15 \mathrm{~g}$ of OMSW, $200 \mathrm{mg}$ of catalyst and with temperature rate of $10^{\circ} \mathrm{C} \cdot \mathrm{min}^{-1}$.

\begin{tabular}{rccc}
\hline & Bio-char yield & Bio-oil yield & Bio-gas yield \\
\hline $200^{\circ} \mathrm{C}$ & $41 \%$ & $23 \%$ & $36 \%$ \\
$250^{\circ} \mathrm{C}$ & $29 \%$ & $28 \%$ & $43 \%$ \\
$350^{\circ} \mathrm{C}$ & $29 \%$ & $35 \%$ & $36 \%$ \\
\hline
\end{tabular}

Table 9. The effect of temperature rate on the conversion yield of the pyrolysis products. The reactions were performed with $15 \mathrm{~g}$ of OMSW and $100 \mathrm{mg}$ of catalyst.

\begin{tabular}{cccc}
\hline & Bio-char yield & Bio-oil yield & Bio-gas yield \\
\hline $450^{\circ} \mathrm{C} ; 10^{\circ} \mathrm{C} \cdot \mathrm{min}^{-1}$ & $25 \%$ & $24 \%$ & $51 \%$ \\
$350^{\circ} \mathrm{C} ; 50^{\circ} \mathrm{C} \cdot \mathrm{min}^{-1}$ & $25 \%$ & $30 \%$ & $45 \%$ \\
Without catalyst & $25 \%$ & $18 \%$ & $57 \%$ \\
$450^{\circ} \mathrm{C} ; 50^{\circ} \mathrm{C} \cdot \mathrm{min}^{-1}$ & $24 \%$ & $27 \%$ & $49 \%$ \\
$450^{\circ} \mathrm{C} ; 50^{\circ} \mathrm{C} \cdot \mathrm{min}^{-1}$ & & & \\
\hline
\end{tabular}

\subsection{Bio-Oil Compositions by GC-MS}

GC-MS analysis was carried out for four samples to identify the components of the obtained bio-oil from different pyrolysis reactions. The reactions were carried out with a temperature rate of $10^{\circ} \mathrm{C} \cdot \mathrm{min}^{-1}$. The retention times obtained from the GC and the molecular structures obtained from Mass Spectroscopy are summarized in Tables 10-12 and Table 13.

In all chromatograms the set of peaks appeared between 18 and 21 min were very close and difficult to identify, so it is suggested that they might be alcohols and ketones (Example 1.2-cyclopentanedione, 3-methyl-1,2-cyclopentanedione, 2-methoxyphenol, 2-methoxy-4-methyl phenol) [67].

The products corresponding to the main peaks with the corresponding retention times of the bio-oil obtained from the pyrolysis of $15 \mathrm{~g}$ of OMSW at $350^{\circ} \mathrm{C}$ without catalyst are summarized in Table 10. High percentage of phenolic compounds were present in the bio-oil such as L-Arginine, N2-[(phenylmethoxy) carbonyl]; 2-methoxyphenol; 2-Methoxy-4-methylphenol; Ethanone,1-(2,4-dihydroxyphenyl); 2,6-dimethoxyphenol; 3,4,5-trimethoxyamphetamine; 4-Ethyl-2methoxyphenol. A large number of oxygenated products with long chemical chains were obtained without catalyst. The products are mainly esters, acids, alcohols, ketones, aldehydes, amides and amines.

The main peaks and the corresponding products of the bio-oil components obtained from pyrolysis of $15 \mathrm{~g}$ of OMSW at $350^{\circ} \mathrm{C}$ in the presence of $200 \mathrm{mg}$ catalyst are summarized in Table 11. It was noticed a total elimination of the phenolic products in the bio-oil in the presence of catalyst. More cyclic and less oxygenated products of small molecules were obtained. Alkane products appear 
Table 10. The results of the GC-MS of the bio-oil derived from the pyrolysis reaction of $15 \mathrm{~g}$ of $\mathrm{OMSW}$ at $350^{\circ} \mathrm{C}$ and without a catalyst.

\begin{tabular}{|c|c|c|}
\hline Retention time (min) & Product Name & Chemical structure \\
\hline 3.5 & Furfural & \\
\hline 4 & 2-propanone, 1-(acetyloxy) & \\
\hline 4.77 & 2-Hexene & \\
\hline 5.99 and 5.95 & 3-Methylpiridazine & \\
\hline 5.7 & 2-Methyl-2-cyclopenten-1-one & \\
\hline 6.92 & 2-Hydroxy-3-methylcyclopent-2-en-1-one & \\
\hline 8.05 & $\begin{array}{c}\text { L-Arginine, } \\
\text { N2-[(phenylmethoxy)carbonyl }]\end{array}$ & \\
\hline 8.39 & 2-Methoxyphenol & \\
\hline 11.18 & 2-Methoxy-4-methylphenol & \\
\hline 11.9 & Vinyl crotonate & \\
\hline 12.9 & cyclobutanol & \\
\hline
\end{tabular}




\section{Continued}

2-Ethanone, 1-(2,4-dihydroxyphenyl)

Ethanone, 1-(2,4-dihydroxyphenyl)

2,6-dimethoxyphenol<smiles>CC(=O)c1ccc(O)cc1O</smiles><smiles>CC(=O)c1ccc(O)cc1O</smiles>

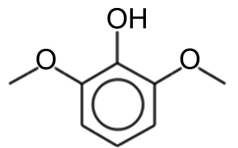<smiles>Cc1cc(C(=O)O)ccc1O</smiles><smiles>COc1cc(CC(C)N)cc(OC)c1OC</smiles>

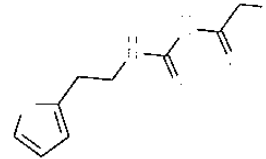

Benzeneethanamine, 3-fluoro-beta, 5-dihydroxy-N-methyl<smiles>CCc1ccc(O)c(OC)c1</smiles>

DL-Alanine ethyl ester<smiles>CCOC(=O)C(C)N</smiles><smiles>CCC(=O)NC(N)=O</smiles> 
Table 11. The results of the GC-MS of the bio-oil after pyrolysis reaction of $15 \mathrm{~g}$ of OMSW in the presence of $200 \mathrm{mg}$ of catalyst at $350^{\circ} \mathrm{C}$.

\begin{tabular}{|c|c|c|}
\hline Retention time (min) & Product Name & Chemical structure \\
\hline 3.48 & acetamide & \\
\hline 3.76 & 1,4-dioxane-2,6-dione & \\
\hline 4.1 & pyrimidine & \\
\hline 4.77 & pyrrole & \\
\hline 4.9 & Propane & \\
\hline 5.3 & glycidol & \\
\hline 6.89 & hydroxyurea & \\
\hline 8.4 & Cyclopent-2-ene-1-one & \\
\hline
\end{tabular}

Table 12. The results of the GC-MS of the bio-oil derived from the pyrolysis reaction of $15 \mathrm{~g}$ of cellulose in the presence of $200 \mathrm{mg}$ of catalyst at $350^{\circ} \mathrm{C}$.

Retention time (min)


Table 13. The results of the GC-MS of the bio-oil derived from the pyrolysis reaction of $15 \mathrm{~g}$ of OMSW in the presence of $200 \mathrm{mg}$ of catalyst at $250^{\circ} \mathrm{C}$.

\begin{tabular}{|c|c|c|}
\hline Retention time (min) & Product Name & Chemical structure \\
\hline 4.015 & acetic acid ethenyl ester & \\
\hline 4.68 & Cyclopent-2-ene-1-one & \\
\hline 4.775 & 2-Oxepanone & \\
\hline 5.9 and 6.9 & 3-methylpiridazine & \\
\hline 6.5 & glycidol & \\
\hline 8.07 & arginine & \\
\hline 8.3 & 2-methoxyphenol & \\
\hline 11.18 & 2-methoxy-4-methylphenol & \\
\hline 11.9 & Vinyl crotonate & \\
\hline 15.49 & 2,6-dimethoxyphenol & \\
\hline 17.57 & $\begin{array}{c}\text { Ethanone, } \\
\text { 1-(2,3,4-trihydroxyphenyl) }\end{array}$ & \\
\hline 21 & 4-ethyl-2-methoxyphenol & \\
\hline
\end{tabular}


in the catalyzed reaction products. Catalytic pyrolysis improves the quality of bio-oil in terms of decreasing the heavy and oxygenated compounds. This is the result of secondary (cracking and recombination) and de-oxygenation reactions occur at the surface of the catalysts and favorite by the Bronsted and Lewis acid sites observed by FTIR. Moreover, Lewis acid sites catalyze reduction reactions such as de-carbonylation of furfural, de-oxygenation of ketones and esters...etc. These results are opposite to that obtained by Christoforou et al. In their published work they, an increase in the percentage of phenolic compounds was observed with increasing viscosity of the obtained liquid [68]. The same results were observed in the GC-MS of the bio-oil obtained from the pyrolysis of $15 \mathrm{~g}$ of cellulose under the same conditions. The main retention times and the corresponding products of the bio-oil obtained from this pyrolysis reaction are summarized in Table 12.

The phenolic products reappeared at low pyrolysis temperature despite the presence of $200 \mathrm{mg}$ of catalyst. The results are summarized in Table 13. Other oxygenated products (ketones and alcohols) were also detected. The cracking, reforming, de-oxygenation and other secondary reactions that occur when the products are in gas phase needs higher temperature. Therefore, our catalyst is not active at low temperature and so the same products as without catalysts were obtained.

\section{Conclusion and Perspectives}

SBA-15 mesoporous silica was successfully synthesized by the sol-gel method with $63 \mathrm{~h}$ maturation step at $35^{\circ} \mathrm{C}$ followed by $33 \mathrm{~h}$ hydrothermal treatment step at $130^{\circ} \mathrm{C}$. An inverse spinel variety of chromium ferrite nanocrystals were obtained perfectly inside the silica pores after replication by the double solvent technique. The obtained catalyst was successfully used in pyrolysis reactions of OMSW and presented an important activity where the bio-oil conversion was improved and a yield up from $24 \%$ to $37 \%$ was obtained. Mainly Bronsted acid sites located at the surface and in the mesopores of the silica were obtained with small concentration of isolated silanol groups. The surface acid sites are of medium and strong Bronsted acidity. Lewis acid sites were created by the insertion of metal oxydes (MO). The weight ratio of OMSW/catalyst, the maximum temperature and the temperature rate were optimized to obtain the highest bio-oil conversion yield. Under the optimal conditions, the bio-oil quality was improved and was demonstrated by the GC-MS results. By using the catalyst, the toxic phenolic components, present in the bio-oil obtained without catalyst, were totally eliminated and deoxygenated; decarboxylated and cyclic components with small molecular size were obtained. The results were close to those obtained under the same conditions in bio-oil derived from the pyrolysis reactions of commercial cellulose. Shorter residence time at high temperature improved the bio-oil conversion yield. Bio-oil yield was increased from $24 \%$ to $27 \%$ when the temperature rate was increased from $10^{\circ} \mathrm{C} \cdot \mathrm{min}^{-1}$ to $50^{\circ} \mathrm{C} \cdot \mathrm{min}^{-1}$. In prospects, 
fast pyrolysis reactions (at very high temperature ramp) at a higher temperature will be performed. Another catalyst bed at the outside of the reactor will be added which may promote the de-oxygenation and the decarbonylation of the pyrolysis products and improves the quality of the resulting bio-oil.

\section{Conflicts of Interest}

The authors declare no conflicts of interest regarding the publication of this paper.

\section{References}

[1] Cao, X. (2003) Climate Change and Energy Development: Implications for Developing Countries. Resources Policy, 29, 61-67. https://doi.org/10.1016/j.resourpol.2004.05.001

[2] (n.d.) United Nations Environment Programme. Integrated Assessment of the Association Agreement with the EU, Lebanon.

[3] International Energy Agency (2018) World Energy Outlook: Executive Summary, Oecd/Iea.

https://webstore.iea.org/download/summary/190?fileName=English-WEO-2018-ES pdf

[4] IEA (2010) IEA World Energy Outlook Report. IEA Annu. Rep. 51, 4847-4862.

[5] IEA (2019) World Energy Outlook 2019. IEA, Paris. https://www.iea.org/reports/world-energy-outlook-2019

[6] Akpan, U.F. and Akpan, G.E. (2012) The Contribution of Energy Consumption to Climate Change: A Feasible Policy Direction. International Journal of Energy Economics and Policy, 2, 21-33.

[7] Li, J., Mohammadi, A. and Maleki, A. (2020) Techno-Economic Analysis of New Integrated System of Humid Air Turbine, Organic Rankine Cycle, and Parabolic Trough Collector. Journal of Thermal Analysis and Calorimetry, 139, 2691-2703. https://doi.org/10.1007/s10973-019-08855-9

[8] Moriarty, P. and Honnery, D. (2012) Preparing for a Low-Energy Future. Futures, 44, 883-892. https://doi.org/10.1016/j.futures.2012.08.002

[9] Sovacool, B.K. (2012) Design Principles for Renewable Energy Programs in Developing Countries. Energy \& Environmental Science, 5, 9157-9162. https://doi.org/10.1039/c2ee22468b

[10] Hoppe, T., Coenen, F. and van den Berg, M. (2016) Illustrating the Use of Concepts from the Discipline of Policy Studies in Energy Research: An Explorative Literature Review. Energy Research \& Social Science, 21, 12-32. https://doi.org/10.1016/j.erss.2016.06.006

[11] Neff, T.L. (1997) Improving Energy Security in Pacific Asia: Diversification and Risk Reduction for Fossil and Nuclear Fuel. Commissioned by the Pacific Asia Regional Energy Security (PARES) Project. http://oldsite.nautilus.org/archives/papers/energy/NeffPARES.pdf

[12] Uchiyama, Y. (2002) Present Efforts of Saving Energy and Future Energy Demand/ Supply in Japan. Energy Conversion and Management, 43, 1123-1131. https://doi.org/10.1016/S0196-8904(02)00003-1

[13] Balat, M. (2010) Security of Energy Supply in Turkey: Challenges and Solutions. Energy Conversion and Management, 51, 1998-2011. 
https://doi.org/10.1016/j.enconman.2010.02.033

[14] Kumar, A., Sah, B., Singh, A.R., Deng, Y., He, X., Kumar, P. and Bansal, R.C. (2017) A Review of Multi Criteria Decision Making (MCDM) towards Sustainable Renewable Energy Development. Renewable and Sustainable Energy Reviews, 69, 596-609. https://doi.org/10.1016/j.rser.2016.11.191

[15] Awerbuch, S., Stirling, A., Jansen, J.C. and Beurskens, L.W.M. (2006) Chapter 13 Full-Spectrum Portfolio and Diversity Analysis of Energy Technologies. In: Leggio, K.B., Bodde, D.L. and Taylor, M.L., Eds., Managing Enterprise Risk, Elsevier Science Ltd., Oxford, 202-222. https://doi.org/10.1016/B978-008044949-4/50046-5

[16] Zhu, D., Mostafa, S., Maleki, A. and Aslani, A. (2020) Analysis of the Robustness of Energy Supply in Japan: Role of Renewable Energy. Energy Reports, 6, 378-391.

https://doi.org/10.1016/j.egyr.2020.01.011

[17] Sricharoenchaikul, V. and Atong, D. (2009) Thermal Decomposition Study on Jatropha curcas L. Waste Using TGA and Fixed Bed Reactor. Journal of Analytical and Applied Pyrolysis, 85, 155-162. https://doi.org/10.1016/j.jaap.2008.11.030

[18] Landberg, L., Mortensen, N.G. and Lundtang Petersen, E. (1995) Wind Resource Assessment and Siting-A Wider Perspective. In: Cross, B., Ed., The World Directory of Renewable Energy Suppliers and Services, James \& James Science Publishers Ltd., 170-176.

[19] Basu, P. (2010) Biomass Gasification and Pyrolysis.

[20] Chen, D., Yin, L., Wang, H. and He, P. (2014) Pyrolysis Technologies for Municipal Solid Waste: A Review. Waste Management, 34, 2466-2486.

https://doi.org/10.1016/j.wasman.2014.08.004

[21] Sharma, S., Meena, R., Sharma, A. and kumar Goyal, P. (2014) Biomass Conversion Technologies for Renewable Energy and Fuels: A Review Note. IOSR Journal of Mechanical and Civil Engineering, 11, 28-35. https://doi.org/10.9790/1684-11232835

[22] Lajili, M., Guizani, C., Escudero Sanz, F.J. and Jeguirim, M. (2018) Fast Pyrolysis and Steam Gasification of Pellets Prepared from Olive Oil Mill Residues. Energy, 150, 61-68. https://doi.org/10.1016/j.energy.2018.02.135

[23] Christoforou, E. and Fokaides, P.A. (2016) A Review of Olive Mill Solid Wastes to Energy Utilization Techniques. Waste Management, 49, 346-363.

https://www.unboundmedicine.com/medline/citation/26810031/A review of olive mill solid wastes to energy utilization techniques https://doi.org/10.1016/j.wasman.2016.01.012

[24] Roig, A., Cayuela, M.L. and Sánchez-Monedero, M.A. (2006) An Overview on Olive Mill Wastes and Their Valorisation Methods. Waste Management, 26, 960-969. https://doi.org/10.1016/j.wasman.2005.07.024

[25] Aggoun, M., Arhab, R., Cornu, A., Portelli, J., Barkat, M. and Graulet, B. (2016) Olive Mill Wastewater Microconstituents Composition According to Olive Variety and Extraction Process. Food Chemistry, 209, 72-80. https://doi.org/10.1016/j.foodchem.2016.04.034

[26] Miranda, T., Arranz, J.I., Montero, I., Román, S., Rojas, C.V. and Nogales, S. (2012) Characterization and Combustion of Olive Pomace and Forest Residue Pellets. Fuel Processing Technology, 103, 91-96. https://doi.org/10.1016/j.fuproc.2011.10.016

[27] Cuomo, F., Venditti, F., Ceglie, A., De Leonardis, A., Macciola, V. and Lopez, F., (2015) Cleaning of Olive Mill Wastewaters by Visible Light Activated Carbon Doped Titanium Dioxide. RSC Advances, 5, 85586-85591. https://doi.org/10.1039/C5RA16860K

[28] Filidei, S., Masciandaro, G. and Ceccanti, B. (2003) Anaerobic Digestion of Olive 
Oil Mill Effluents: Evaluation of Wastewater Organic Load and Phytotoxicity Reduction. Water, Air, \& Soil Pollution, 145, 79-94.

https://doi.org/10.1023/A:1023619927495

[29] Hodaifa, G., Ochando-Pulido, J.M., Rodriguez-Vives, S. and Martinez-Ferez, A. (2013) Optimization of Continuous Reactor at Pilot Scale for Olive-Oil Mill Wastewater Treatment by Fenton-Like Process. Chemical Engineering Journal, 220, 117 124. https://doi.org/10.1016/j.cej.2013.01.065

[30] Cuomo, F., Venditti, F., Cinelli, G., Ceglie, A. and Lopez, F. (2016) Olive Mill Wastewater (OMW) Phenol Compounds Degradation by Means of a Visible Light Activated Titanium Dioxide-Based Photocatalyst. Zeitschrift für Physikalische Chemie, 230, 1269-1280. https://doi.org/10.1515/zpch-2015-0725

[31] Nieto, L.M., Hodaifa, G., Rodríguez, S., Giménez, J.A. and Ochando, J. (2011) Degradation of Organic Matter in Olive-Oil Mill Wastewater through Homogeneous Fenton-Like Reaction. Chemical Engineering Journal, 173, 503-510. https://doi.org/10.1016/j.cej.2011.08.022

[32] Jeguirim, M., Chouchène, A., Réguillon, A.F., Trouvé, G. and Le Buzit, G. (2012) A New Valorisation Strategy of Olive Mill Wastewater: Impregnation on Sawdust and Combustion. Resources, Conservation \& Recycling, 59, 4-8. https://doi.org/10.1016/j.resconrec.2011.03.006

[33] Kraiem, N., Jeguirim, M., Limousy, L., Lajili, M., Dorge, S., Michelin, L. and Said, R. (2014) Impregnation of Olive Mill Wastewater on Dry Biomasses: Impact on Chemical Properties and Combustion Performances. Energy, 78, 479-489. https://doi.org/10.1016/j.energy.2014.10.035

[34] Lajili, M., Limousy, L. and Jeguirim, M. (2014) Physico-Chemical Properties and Thermal Degradation Characteristics of Agropellets from Olive Mill By-Products/ Sawdust Blends. Fuel Processing Technology, 126, 215-221. https://doi.org/10.1016/j.fuproc.2014.05.007

[35] Lajili, M., Jeguirim, M., Kraiem, N. and Limousy, L. (2015) Performance of a Household Boiler Fed with Agropellets Blended from Olive Mill Solid Waste and Pine Sawdust. Fuel, 153, 431-436. https://doi.org/10.1016/j.fuel.2015.03.010

[36] Brlek, T., Pezo, L., Voća, N., Krička, T., Vukmirović, Đ., Čolović, R. and BodrožaSolarov, M. (2013) Chemometric Approach for Assessing the Quality of Olive Cake Pellets. Fuel Processing Technology, 116, 250-256. https://doi.org/10.1016/j.fuproc.2013.07.006

[37] Doassans-Carrère, N., Muller, S. and Mitzkat, M. (2014) REVE-A New Industrial Technology for Biomass Torrefaction: Pilot Studies. Fuel Processing Technology, 126, 155-162. https://doi.org/10.1016/j.fuproc.2014.04.026

[38] Peduzzi, E., Boissonnet, G., Haarlemmer, G., Dupont, C. and Maréchal, F. (2014) Torrefaction Modelling for Lignocellulosic Biomass Conversion Processes. Energy, 70, 58-67. https://doi.org/10.1016/j.energy.2014.03.086

[39] Aboagye, D., Banadda, N., Kiggundu, N. and Kabenge, I. (2017) Assessment of Orange Peel Waste Availability in Ghana and Potential Bio-Oil Yield Using Fast Pyrolysis. Renewable and Sustainable Energy Reviews, 70, 814-821. https://doi.org/10.1016/j.rser.2016.11.262

[40] Hu, X. and Gholizadeh, M. (2019) Biomass Pyrolysis: A Review of the Process Development and Challenges from Initial Researches Up to the Commercialisation Stage. Journal of Energy Chemistry, 39, 109-143. https://doi.org/10.1016/j.jechem.2019.01.024

[41] Uslu, A., Faaij, A.P.C. and Bergman, P.C.A. (2008) Pre-Treatment Technologies, 
and Their Effect on International Bioenergy Supply Chain Logistics. Techno-Economic Evaluation of Torrefaction, Fast Pyrolysis and Pelletisation. Energy, 33, 12061223. https://doi.org/10.1016/j.energy.2008.03.007

[42] Nik-Azar, M., Hajaligol, M.R., Sohrabi, M. and Dabir, B. (1997) Mineral Matter Effects in Rapid Pyrolysis of Beech Wood. Fuel Processing Technology, 51, 7-17. https://doi.org/10.1016/S0378-3820(96)01074-0

[43] Mohan, D., Pittman, C.U. and Steele, P.H. (2006) Pyrolysis of Wood/Biomass for Bio-Oil: A Critical Review. Energy \& Fuels, 20, 848-889. https://doi.org/10.1021/ef0502397

[44] Boroson, M.L., Howard, J.B., Longwell, J.P. and Peters, W.A. (1989) Product Yields and Kinetics from the Vapor Phase Cracking of Wood Pyrolysis Tars. AIChE Journal, 35, 120-128. https://doi.org/10.1002/aic.690350113

[45] Zou, L. and Jiang, Y. (2010) A Simple Criterion for the Stability of Linear System with Constant Coefficients. Advanced Materials Research, 108-111, 359-362. https://doi.org/10.4028/www.scientific.net/AMR.108-111.359

[46] Uzun, B.B. and Kanmaz, G. (2013) Effect of Operating Parameters on Bio-Fuel Production from Waste Furniture Sawdust. Waste Management \& Research, 31, 361 367. https://doi.org/10.1177/0734242X12470402

[47] Abnisa, F., Daud, W.M.A.W., Husin, W.N.W. and Sahu, J.N. (2011) Utilization Possibilities of Palm Shell as a Source of Biomass Energy in Malaysia by Producing Bio-Oil in Pyrolysis Process. Biomass and Bioenergy, 35, 1863-1872.

https://doi.org/10.1016/j.biombioe.2011.01.033

[48] Zhang, H., Zheng, J., Xiao R., Jia, Y., Shen, D., Jin, B. and Xiao, G. (2014) Study on Pyrolysis of Pine Sawdust with Solid Base and Acid Mixed Catalysts by Thermogravimetry-Fourier Transform Infrared Spectroscopy and Pyrolysis-Gas Chromatography/Mass Spectrometry. Energy \& Fuels, 28, 4294-4299. https://doi.org/10.1021/ef500176w

[49] Lu, Q., Zhang, Z.-F., Dong, C.-Q. and Zhu, X.-F. (2010) Catalytic Upgrading of Biomass Fast Pyrolysis Vapors with Nano Metal Oxides: An Analytical Py-GC/MS Study. Energies, 3, 1805-1820. https://doi.org/10.3390/en3111805

[50] Hattori, H. (2001) Solid Base Catalysts: Generation of Basic Sites and Application to Organic Synthesis. Applied Catalysis A: General, 222, 247-259. https://doi.org/10.1016/S0926-860X(01)00839-0

[51] Rahimi, N. and Karimzadeh, R. (2011) Catalytic Cracking of Hydrocarbons over Modified ZSM-5 Zeolites to Produce Light Olefins: A Review. Applied Catalysis A: General, 398, 1-17. https://doi.org/10.1016/j.apcata.2011.03.009

[52] Jacobson, K., Maheria, K.C. and Dalai, A.K. (2013) Bio-Oil Valorization: A Review. Renewable and Sustainable Energy Reviews, 23, 91-106.

https://doi.org/10.1016/j.rser.2013.02.036

[53] Taarning, E., Osmundsen, C.M., Yang, X., Voss, B., Andersen, S.I. and Christensen, C.H. (2011) Zeolite-Catalyzed Biomass Conversion to Fuels and Chemicals. Energy \& Environmental Science, 4, 793-804. https://doi.org/10.1039/C004518G

[54] Tabaja, N., Brouri, D., Casale, S., Zein, S., Jaafar, M., Selmane, M., Toufaily, J., Davidson, A. and Hamieh, T. (2019) Use of SBA-15 Silica Grains for Engineering Mixtures of Oxides $\mathrm{CoFe}$ and $\mathrm{NiFe}$ for Advanced Oxidation Reactions under Visible and NIR. Applied Catalysis B: Environmental, 253, 369-378. https://doi.org/10.1016/j.apcatb.2019.04.073

[55] Lyu, G., Wu, S. and Zhang, H. (2015) Estimation and Comparison of Bio-Oil Components from Different Pyrolysis Conditions. Frontiers in Energy Research, 3, Ar- 
ticle 28. https://doi.org/10.3389/fenrg.2015.00028

[56] Tabaja, N., Casale, S., Brouri, D., Davidson, A., Obeid, H., Toufaily, J. and Hamieh, T. (2015) Quantum-Dots Containing Fe/SBA-15 Silica as "Green" Catalysts for the Selective Photocatalytic Oxidation of Alcohol (Methanol, under Visible Light). Comptes Rendus Chimie, 18, 358-367. https://doi.org/10.1016/j.crci.2015.01.010

[57] Gallo, J.M.R., Bisio, C., Gatti, G., Marchese, L. and Pastore, H.O. (2010) Physicochemical Characterization and Surface Acid Properties of Mesoporous [Al]-SBA-15 Obtained by Direct Synthesis. Langmuir, 26, 5791-5800.

https://doi.org/10.1021/la903661q

[58] Góra-Marek, K., Derewiński, M., Sarv, P. and Datka, J. (2005) IR and NMR Studies of Mesoporous Alumina and Related Aluminosilicates. Catalysis Today, 101, 131 138. https://doi.org/10.1016/j.cattod.2005.01.010

[59] Hewer, T.L.R., Souza, A.G.F., Roseno, K.T.C., Moreira, P.F., Bonfim, R., Alves, R.M.B. and Schmal, M. (2018) Influence of Acid Sites on the Hydrodeoxygenation of Anisole with Metal Supported on SBA-15 and SAPO-11. Renewable Energy, 119, 615624. https://doi.org/10.1016/j.renene.2017.12.044

[60] AA, Z., Kalogiannis, G., Kappas, E. and AJ, K. (2000) Olive Residues (Cuttings and Kernels) Rapid Pyrolysis Product Yields and Kinetics. Biomass \& Bioenergy, 18, 411 420. https://doi.org/10.1016/S0961-9534(00)00002-7

[61] Zabaniotou, A., Ioannidou, O., Antonakou, E. and Lappas, A. (2008) Experimental Study of Pyrolysis for Potential Energy, Hydrogen and Carbon Material Production from Lignocellulosic Biomass. International Journal of Hydrogen Energy, 33, 2433 2444. https://doi.org/10.1016/j.ijhydene.2008.02.080

[62] Zanzi, R., Sjöström, K. and Björnbom, E. (2002) Rapid Pyrolysis of Agricultural Residues at High Temperature. Biomass and Bioenergy, 23, 357-366. https://doi.org/10.1016/S0961-9534(02)00061-2

[63] Şensöz, S., Demiral, I. and Gerçel, H.F. (2006) Olive Bagasse (Olea europea L.) Pyrolysis. Bioresource Technology, 97, 429-436. https://doi.org/10.1016/j.biortech.2005.03.007

[64] Encinar, J.M., González, J.F., Martínez, G. and Román, S. (2009) Catalytic Pyrolysis of Exhausted Olive Oil Waste. Journal of Analytical and Applied Pyrolysis, 85, 197 203. https://doi.org/10.1016/j.jaap.2008.11.018

[65] Demiral, I. and Şensöz, S., (2008) The Effects of Different Catalysts on the Pyrolysis of Industrial Wastes (Olive and Hazelnut Bagasse). Bioresource Technology, 99, 8002-8007. https://doi.org/10.1016/j.biortech.2008.03.053

[66] Valenzuela-Calahorro, C., Bernalte-Garcia, A., Gómez-Serrano, V. and BernalteGarcía, M.J. (1987) Influence of Particle Size and Pyrolysis Conditions on Yield, Density and Some Textural Parameters of Chars Prepared from Holm-Oak Wood. Journal of Analytical and Applied Pyrolysis, 12, 61-70. https://doi.org/10.1016/0165-2370(87)80015-3

[67] Chang, S., Zhao, Z., Zhang, W., Zheng, A., Wu, W. and Li, H. (2011) Comparison of Chemical Composition and Structure of Different Kinds of Bio-Oils. Journal of Fuel Chemistry and Technology, 39, 746-753.

[68] Christoforou, E.A., Fokaides, P.A., Banks, S.W., Nowakowski, D., Bridgwater, A.V., Stefanidis, S., Kalogiannis, K.G., Iliopoulou, E.F. and Lappas, A.A. (2018) Comparative Study on Catalytic and Non-Catalytic Pyrolysis of Olive Mill Solid Wastes. Waste and Biomass Valorization, 9, 301-313. https://doi.org/10.1007/s12649-016-9809-5 